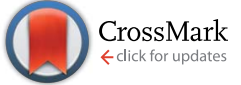

Cite this: Chem. Sci., 2014, 5, 4189

Received 9th June 2014

Accepted 1st July 2014

DOI: $10.1039 / c 4 s c 01696 c$

www.rsc.org/chemicalscience

\title{
Ultrafast and reversible thermochromism of a conjugated polymer material based on the assembly of peptide amphiphilestt
}

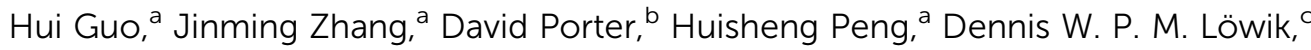 \\ Yu Wang, ${ }^{a}$ Zhidong Zhang, ${ }^{a}$ Xin Chen ${ }^{a}$ and Zhengzhong Shao*a
}

\begin{abstract}
The translation of the colour change that occurs in chameleons into synthetic functional materials has attracted increasing interest, and conjugated polymers such as polydiacetylenes that undergo chromatic transitions under heating represent one of the most studied systems. However, they suffer from a slow and irreversible colour change, typically at low temperatures, e.g., 50-90 ${ }^{\circ} \mathrm{C}$, which limits their sensing applications. In addition, they occur as powders or films and cannot satisfy the requirements for wearable electronics, a mainstream direction in sensing. Herein, it is shown that the introduction of a peptide to the side chain enables a continuous polydiacetylene fibre to exhibit ultrafast, reversible thermochromatic transitions at a high temperature of $200{ }^{\circ} \mathrm{C}$. In particular, the reversible thermochromism occurs even at a temperature change rate of $5000 \mathrm{~K} \mathrm{~s}^{-1}$, much higher than the typical $\sim 1 \mathrm{~K} \mathrm{~s}^{-1}$ of other sensing polymers. The formation of a hierarchically assembled structure is responsible for this remarkable chromatism. In addition, a general and effective model is discovered to quantitatively predict the critical temperature of the colour change in polydiacetylene and guide the development of chromatic materials.
\end{abstract}

\section{Introduction}

A rapid and reversible colour transition in response to environmental changes is crucial to the survival of chameleons, and is also the goal of bio-inspired synthetic sensing materials. ${ }^{1}$ Some of the most widely investigated materials are conjugated polymers such as polydiacetylene (PDA) derivatives that exhibit obvious colour changes, typically from blue to red under heating, and generally in a temperature range of 50-90 ${ }^{\circ} \mathrm{C}$ due to a decrease in the conjugation length of the PDA backbone. ${ }^{2,3}$ The chromatic transition of PDA can be directly detected by the naked eye, enabling a broad spectrum of optoelectronic and sensing applications. ${ }^{4-9}$ However, the available PDA materials

\footnotetext{
${ }^{a}$ State Key Laboratory of Molecular Engineering of Polymers, Advanced Materials Laboratory, Department of Macromolecular Science, Fudan University, Shanghai 200433, People's Republic of China.E-mail: zzshao@fudan.edu.cn

${ }^{b}$ Department of Zoology, University of Oxford, South Parks Road, Oxford OX1 3PS, United Kingdom

'Institute for Molecules and Materials, Radboud University Nijmegen, Heyendaalseweg 135, 6525 AJ Nijmegen, The Netherlands

$\dagger$ Electronic supplementary information (ESI) available: Mechanical properties of materials, pictures of membranes at high temperature, Raman spectra at varying temperatures, thermogravimetric analysis, DSC results and videos. See DOI: 10.1039/c4sc01696c

\$ In memory of Prof. David Porter (16th Nov. 1952-2nd July 2014), who was a senior and much valued visiting scholar in the State Key Laboratory of Molecular Engineering of Polymers at Fudan University.
}

often suffer from a slow response time (tens of seconds to minutes), low reversibility (tens of cycles or even irreversible), a narrow working temperature range (less than $90{ }^{\circ} \mathrm{C}$ without the introduction of inorganic components) and poor mechanical properties, mainly due to the relatively low structural regularity and strength of molecular interactions. Based on the same reasons, the available chromatic polymers have generally been made into powders or films, and it remains challenging to achieve continuous fibres that are required for wearable electronics, which are a promising direction in sensing applications. To date, many strategies towards the design of thermochromatic PDA and other polymer materials have been attempted, ${ }^{3}$ while it has remained impossible to overcome either of the above long-standing challenges.

Peptide-based supramolecular materials are widely studied for their strong and directional interactions among subunits. ${ }^{10-16}$ In this work, by incorporating the well-defined self-assembling performance of peptide-based amphiphiles, we present a general and efficient strategy to synthesize continuous thermochromatic PDA fibres as well as uniform films and gels through an easy solution process. These polymer fibres are strong and exhibit a remarkably rapid response even at high temperatures of up to $200{ }^{\circ} \mathrm{C}$. In addition, the critical temperature of the thermochromatic transition can be finely tuned by varying the length of the alkyl chains. For the first time, an effective model that can quantitatively predict the critical temperature is developed for chromatic polymers. 


\section{Experimental}

\section{Preparation of PAs}

Peptide GAGAGAGY was prepared as reported in our previous work. ${ }^{17}$ 10,12-Pentacosadiynoic acid $(0.24 \mathrm{mmol})$ was dissolved in DMF $(20 \mathrm{~mL})$. After addition of $O$-(benzotriazol-1-yl)$N, N, N^{\prime}, N^{\prime}$-tetramethyluronium tetrafluoroborate $(0.24 \mathrm{mmol})$ and diisopropylethylamine $(0.24 \mathrm{mmol})$, the solution was stirred at room temperature for $30 \mathrm{~min}$ to activate the carboxyl group of 10,12-pentacosadiynoic acid. Then GAGAGAGY (0.20 $\mathrm{mmol}$ ), dissolved in $10 \mathrm{~mL}$ DMF, was added dropwise to the solution. After $3 \mathrm{~h}$ at $0{ }^{\circ} \mathrm{C}$ the DMF was removed under vacuum and the residual solid was dissolved in $\mathrm{NaOH}(10 \mathrm{~mL}, 0.1 \mathrm{M})$. The solution was acidified with $\mathrm{HCl}$ to give a precipitate. The solid was washed with water and lyophilized. $\mathrm{C}_{25}$-GAGAGAGY was characterized by liquid chromatography-electrospray ionization mass spectrometry (LC/ESI-MS) $(\mathrm{m} / \mathrm{z}=979.88$, expected $\left.979.87[\mathrm{M}+\mathrm{H}]^{+}\right)$, MALDI-TOF $(\mathrm{m} / \mathrm{z}=1023.88$, expected 1023.83 $\left.[\mathrm{M}+2 \mathrm{Na}-\mathrm{H}]]^{+}\right) ;{ }^{1} \mathrm{H}$ NMR [400 MHz, DMSO-d $\left.{ }_{6}, \mathrm{ppm}\right]: \delta 0.82(\mathrm{t}$, $3 \mathrm{H}), 1.10-1.49(\mathrm{~m}, 41 \mathrm{H}), 2.07(\mathrm{t}, 2 \mathrm{H}), 2.23(\mathrm{t}, 3 \mathrm{H}), 2.76(\mathrm{~m}, 2 \mathrm{H})$, $3.67(\mathrm{~m}, 8 \mathrm{H}), 4.24(\mathrm{~m}, 4 \mathrm{H}), 6.61(\mathrm{~d}, 2 \mathrm{H}), 6.95(\mathrm{~d}, 2 \mathrm{H}), 7.96(\mathrm{~m}$, $8 \mathrm{H}), 9.17(\mathrm{~s}, 1 \mathrm{H}) . \mathrm{C}_{23}$-GAGAGAGY was prepared and characterized analogously, using peptide GAGAGAGY and 10,12-tricosadiynoic acid. LC/ESI-MS $(m / z=951.38$, expected 951.83 [M + $\left.\mathrm{H}]^{+}\right)$; MALDI-TOF $\left(m / z=995.79\right.$, expected 995.79 $\left.[\mathrm{M}+2 \mathrm{Na}-\mathrm{H}]^{+}\right)$; ${ }^{1} \mathrm{H}$ NMR [400 MHz, DMSO-d $\left.{ }_{6}, \mathrm{ppm}\right]: \delta 0.82(\mathrm{t}, 3 \mathrm{H}), 1.05-1.49(\mathrm{~m}$, $37 \mathrm{H}), 2.05(\mathrm{t}, 2 \mathrm{H}), 2.24(\mathrm{t}, 3 \mathrm{H}), 2.76(\mathrm{~m}, 2 \mathrm{H}), 3.67(\mathrm{~m}, 8 \mathrm{H}), 4.21$ $(\mathrm{m}, 4 \mathrm{H}), 6.60(\mathrm{~d}, 2 \mathrm{H}), 6.95(\mathrm{~d}, 2 \mathrm{H}), 8.02(\mathrm{~m}, 8 \mathrm{H}), 9.15(\mathrm{~s}, 1 \mathrm{H})$.

\section{Preparation of fibres, membranes and gels}

$\mathrm{C}_{25}$-GAGAGAGY/C 23 -GAGAGAGY $(0.050 \mathrm{mmol})$ was dissolved in $\mathrm{NaOH}(5 \mathrm{~mL}, 0.01 \mathrm{M})$ before adjusting the $\mathrm{pH}$ to 7 using concentrated hydrochloric acid. The solution was heated to 60 ${ }^{\circ} \mathrm{C}$ to dissolve the solid and then cooled to room temperature slowly. A colourless or light red gel fibre was obtained by injecting the solution into $\mathrm{HCl}(0.1 \mathrm{M})$ with a $1 \mathrm{~mL}$ syringe. After irradiation with UV light (WFH-204B, $254 \mathrm{~nm}$ ) at a distance of 5 $\mathrm{cm}$ for $3 \mathrm{~min}$, a blue PA-PDA fibre was obtained. Membranes were prepared by coating glass slides and bulk gels were prepared by molding in plastic moulds. These were irradiated in the same way as the fibres. The fibres and membranes were dried in air before heat testing.

\section{Measurements}

UV-vis spectroscopy: the membranes were analysed with a SHIMADZU UV-2550 with temperature controlling accessories. The membranes were placed on a quartz cuvette and equilibrated at each temperature for $3 \mathrm{~min}$. FE-SEM: the gel fibres and membranes were frozen using liquid nitrogen before freezedrying, and sputtered with gold before imaging on a Hitachi S4800 FE-SEM, operated at $1.0 \mathrm{kV}$. FT-IR spectroscopy: transmission FTIR absorption spectra were collected on a Nicolet Nexus-470 spectrometer with the PA-PDA membranes between $\mathrm{KBr}$ plates. Samples were equilibrated at each temperature for 3 min before scanning 64 times. XRD: the X-ray scans of the PAPDA materials were performed with a D8 Discovery (Bruker) diffractometer, on a 16407 high-temperature stage. The X-ray source was $\mathrm{Cu} \mathrm{K} \alpha$ radiation $(\lambda=1.5418 \AA)$, at $40 \mathrm{~mA}$ and $40 \mathrm{kV}$. The heating rate was $5{ }^{\circ} \mathrm{C} \min ^{-1}$, and the sample was stabilized for $1 \mathrm{~min}$ at each temperature before measurement. Raman spectra: Raman spectra were recorded on a Renishaw inVia Reflex Raman Spectrometer, with a $785 \mathrm{~nm}$ semiconductor laser. The samples were scanned 4 times after equilibration for $3 \mathrm{~min}$ at each temperature. TGA: thermogravimetric analysis was performed on a Pyris- 1 thermogravimetric analyzer, with a heating rate of $10{ }^{\circ} \mathrm{C}$ per minute from $30{ }^{\circ} \mathrm{C}$ to $600{ }^{\circ} \mathrm{C}$, in air. DSC: DSC was performed on a TA Q2000 instrument, with a heating rate of $10{ }^{\circ} \mathrm{C}$ per minute and a cooling rate of $20{ }^{\circ} \mathrm{C}$ per minute from $20{ }^{\circ} \mathrm{C}$ to $100{ }^{\circ} \mathrm{C}$. Flash DSC: flash DSC was performed on a fast scanning calorimeter (Flash DSC 1, Mettler Toledo), with the heating rate and cooling rate stated in the main text. In flash DSC analysis, silicone oil was used to fix the samples onto the stage.

\section{Results and discussion}

\section{Thermochromism and mechanical properties}

The octapeptide GAGAGAGY, originally obtained from hydrolyzed Bombyx mori silk fibroin, ${ }^{17}$ was coupled with 10,12-pentacosadiynoic acid to yield the peptide-based amphiphilic (PA) diacetylene, i.e., $\mathrm{C}_{25}$-GAGAGAGY (Scheme 1a). As expected, $\mathrm{C}_{25}{ }^{-}$ GAGAGAGY self-assembled into nanoribbons that further aggregated into bundles in a parallel fashion at a $\mathrm{pH}$ of around 7 in aqueous solution $(1 \mathrm{wt} \%) .{ }^{18}$ When the $\mathrm{pH}$ was decreased, the solution gelled and could then be made into various shapes such as fibres (Fig. 1a and b), membranes (Fig. 1c) and bulk gels (Fig. 1d), depending on the methods used for extrusion, coating and molding, respectively. At the same time, the conjugated triple bonds within the assembly fulfill the topological conditions for reaction and can be photo-polymerized rapidly to form peptide-based amphiphilic polydiacetylene (PA-PDA) under UV light. Interestingly, the resulting materials consisted of nanofibrillar microstructures, as observed by field emission scanning electron microscopy (FESEM) (Fig. 2a and b). To extensively explore the structure and thermochromatic properties of PA-PDA, besides fibres, both films and gels were also carefully investigated.

These materials displayed noteworthy mechanical properties, as illustrated by a tensile modulus of $3 \mathrm{GPa}$ for the fibres and a compression modulus of $10 \mathrm{kPa}$ for the gels (Fig. S1 ESI $\dagger$ ). It is worthwhile to note that the modulus of the fibre is at the same order of magnitude as the generic elastic modulus of glassy polymers, ${ }^{19}$ showing promise for wearable electronic devices. The PA-PDA fibre exhibited ultrafast, reversible

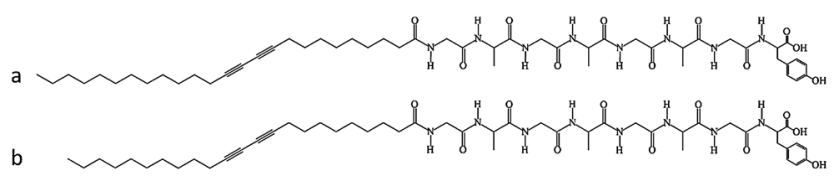

Scheme 1 Peptide amphiphile molecules used in this study. (a) $\mathrm{C}_{25^{-}}$ GAGAGAGY. (b) $\mathrm{C}_{23}$-GAGAGAGY. 


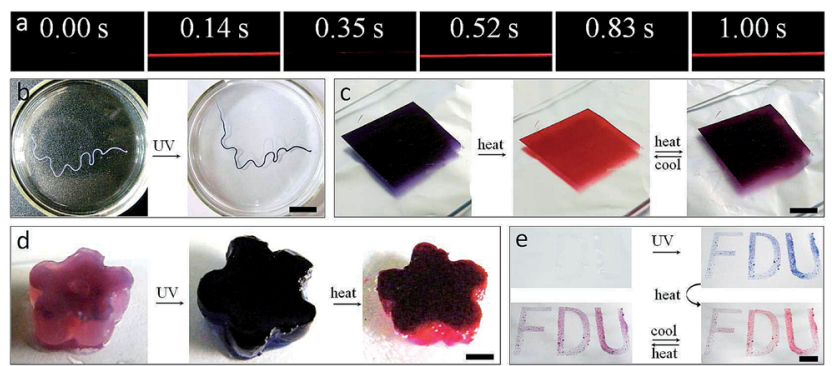

Fig. 1 Thermochromism of the PA-PDA materials. (a) Screenshots of the PA-PDA fibre over 1 second upon heating and cooling. (b) The light red fibre obtained through extrusion turns blue under UV light. (c) PAPDA membranes (dried, left to right): at room temperature, at $80^{\circ} \mathrm{C}$, after cooling to room temperature. (d) (Left to right) PA hydrogel, PAPDA hydrogel, sample after heating at $80{ }^{\circ} \mathrm{C}$. (e) (Clockwise) PA hydrogel $(0.2 \mathrm{wt} \%)$ : sprayed into a pattern, after UV irradiation, thermochromatic behavior of sprayed pattern. The length of the fibre in (a) is $1 \mathrm{~cm}$. The bars represent (b) $1 \mathrm{~cm}$, (c) $2 \mathrm{~cm}$, (d) $1 \mathrm{~cm}$, (e) $3 \mathrm{~cm}$.
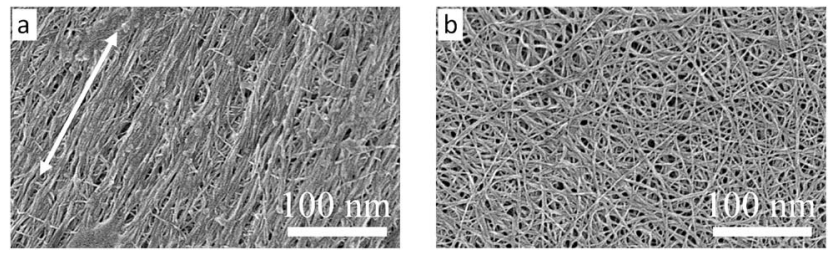

Fig. 2 FE-SEM images of PA-PDA fibre (a) and membrane (b). The nanoribbon bundles are highly oriented in the shear direction (white arrow) in the fibre and distributed randomly in the membrane.

thermochromism. At least 3 chromatic transition cycles could be completed in 1 second upon heating and cooling (Fig. 1a, video $\mathrm{S} 1 \dagger$ ). Such a rapid thermochromism has not been previously observed for PDA or other sensing polymers. Rapid thermochromism was also observed in the PA-PDA film and gel. As an application demonstration, PA-PDA hydrogels were sprayed into a pattern for a reversible chromatic transition under heating (Fig. 1e).

To further investigate the chromatic transition, the optical properties of the PA-PDA films at various temperatures were characterized using UV-vis spectroscopy. The peak at $630 \mathrm{~nm}$ was associated with the blue phase and the peak at $540 \mathrm{~nm}$ corresponded to the red phase (Fig. 3a). The peak intensity at $630 \mathrm{~nm}$ decreased while the intensity of the one at $540 \mathrm{~nm}$ increased with increasing temperature, which was also verified by the colour change from blue to red. When the temperature was decreased, the original UV-vis spectrum was recovered to a large extent after the first cycle and reached an equilibrium from the second cycle (Fig. 3b), while the rapid reversibility was maintained even after dozens of thermal cycles (Fig. 3c, CR (colorimetric response) ${ }^{20}\left(B_{0}-B_{\text {temperature }}\right) / B_{0} \times 100 \%$, $B_{\text {temperature }}=A_{630} /\left(A_{630}+A_{540}\right)$, where $B_{0}$ is the initial value and $A_{\text {wavelength }}$ is the absorbance at the corresponding wavelength). Furthermore, different heating temperatures corresponded to different recovered spectra which, in our opinion, is due to a partly irreversible conformational transition in the first
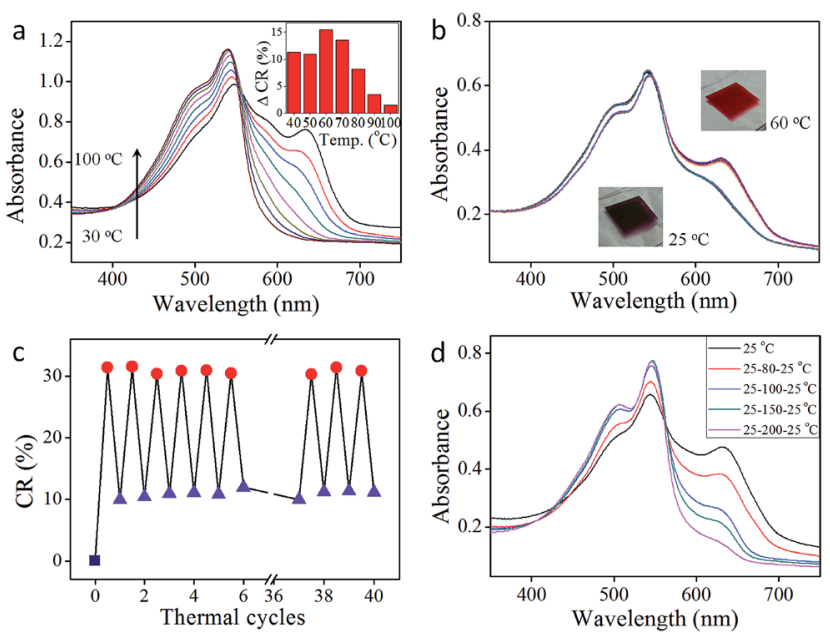

Fig. 3 UV-vis characterization of the thermochromism of the PA-PDA materials. (a) UV-vis spectra of PDA membranes at $30-100{ }^{\circ} \mathrm{C}$ (inset, $\Delta C R$ values at increasing temperatures). (b) UV-vis spectra of cycles between $25^{\circ} \mathrm{C}$ and $60{ }^{\circ} \mathrm{C}$. (c) $\mathrm{CR}$ values of scores of thermal cycles between $25^{\circ} \mathrm{C}$ and $60{ }^{\circ} \mathrm{C}$. (d) UV-vis spectra of PDA membranes which were heated to $80^{\circ} \mathrm{C}, 100^{\circ} \mathrm{C}, 150^{\circ} \mathrm{C}$ or $200^{\circ} \mathrm{C}$ before cooling to $25^{\circ} \mathrm{C}$.

heating stage (Fig. 3d). Nevertheless, the PA-PDA materials showed a reversible thermochromism even at a high temperature of $200{ }^{\circ} \mathrm{C}$ (Fig. S2, video S2 $\dagger$ ), much higher than the reversibility up to $90^{\circ} \mathrm{C}$ that was observed in other PDA systems. It is even higher than the $145^{\circ} \mathrm{C}$ limit observed in a PDA/silica composite. $^{21}$

\section{Structural characterization and mechanism}

Fourier transform infrared (FTIR) spectroscopy, X-ray diffraction (XRD) and Raman spectroscopy were used to investigate the structural transformation during heating. Fig. $4 \mathrm{a}$ and $\mathrm{b}$ compare the FTIR spectra of a PA-PDA film at different temperatures. The $\nu_{\text {as }}\left(\mathrm{CH}_{2}\right)\left(2920 \mathrm{~cm}^{-1}\right)$ and $\nu_{\mathrm{s}}\left(\mathrm{CH}_{2}\right)(2850$ $\mathrm{cm}^{-1}$ ) vibrations were shifted to higher frequencies, suggesting a more disordered conformation of the PDA segments. ${ }^{22}$ However, the peak at $1628 \mathrm{~cm}^{-1}$, ascribed to a peptide $\beta$-sheet, showed hardly any shift, indicating that the $\beta$-sheets formed by the PA segment were stable during heating. This conclusion was also verified by XRD at different temperatures (Fig. 5a). The peak at $2 \theta$ of $19.9^{\circ}(4.46 \AA)$ that corresponds to the hydrogen bond spacing of the $\beta$-sheet structure ${ }^{23}$ remained constant and only shifted a little at $200{ }^{\circ} \mathrm{C}$, while the peak at $2 \theta$ of $22.6^{\circ}$ (3.93 $\AA$ ) that is attributed to the lattice of the alkyl chains ${ }^{24}$ was obviously shifted and vanished with increasing temperature. In addition, the Raman spectra (Fig. $5 \mathrm{~b}$ ) illustrated that $\mathrm{C}=\mathrm{C}$ and $\mathrm{C} \equiv \mathrm{C}$ undergo a conformational transition during the heating process, as can be deduced from the shift of the peaks at 1454 $\mathrm{cm}^{-1}$ and $2086 \mathrm{~cm}^{-1}$ at room temperature to $1513 \mathrm{~cm}^{-1}$ and $2117 \mathrm{~cm}^{-1}$ at high temperature, respectively., ${ }^{7,25}$ Obviously, the higher wavenumber corresponds to the higher energy of the conjugated $\mathrm{C}=\mathrm{C}$ and $\mathrm{C} \equiv \mathrm{C}$ and the stronger absorption at the lower wavelength peak in the UV-vis spectrum, with the material 

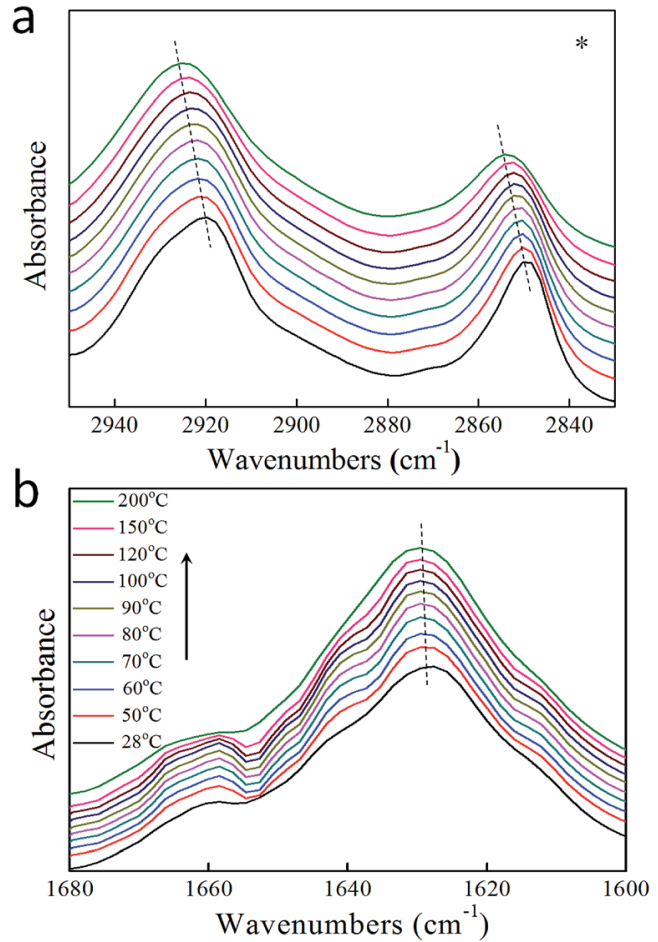

Fig. 4 FTIR spectra of PA-PDA membranes at different temperatures ((a) and (b) share the legend).
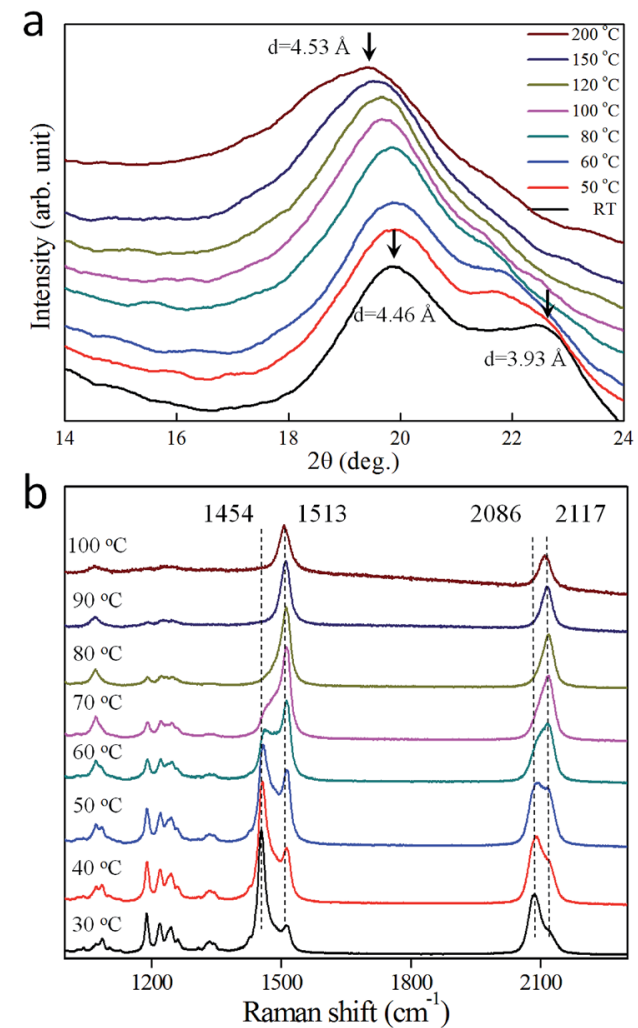

Fig. 5 (a) X-ray diffraction analysis of PA-PDA at different temperatures. (b) Raman spectra of PA-PDA membranes at different temperatures. showing a red colour. Furthermore, the Raman spectra from 30 to $80{ }^{\circ} \mathrm{C}$ also corroborated that the conformational transitions of $\mathrm{C}=\mathrm{C}$ or $\mathrm{C} \equiv \mathrm{C}$ were reversible (Fig. S3, ESI $\dagger$ ). The FTIR spectra in combination with the XRD patterns and Raman spectra demonstrated that the two segments of the molecule behaved differently upon heating: the peptide segment was stable, without obvious conformational transition or thermal degradation (Fig. S4, ESI $\dagger$ ), while the conjugated double and triple bonds within the alkyl chain segment experienced a reversible conformational transition.

Therefore, it can be concluded that the double and triple bonds were changed from all-trans configurations to partly-cis configurations as the mobility of the alkyl chains increased during heating. Different from other studies, ${ }^{26}$ the $\beta$-sheets of the peptide side chains restricted the disorder and the molecular separation remained stable under heating at high temperatures, which drove the PDA backbone back to its original co-planar configuration upon cooling. In the first heating cycle, the partly unstable structures were disrupted and could not be recovered completely, resulting in a partial recovery after the first cycle.

\section{Transition temperature investigation and modelling}

DSC was employed to study the transition temperature of the PA-PDA materials to gain more insight into the thermochromatic behavior resulting from the thermal motion of the alkyl chain. Only one endothermic peak was observed at about $60^{\circ} \mathrm{C}$ in the temperature range of -80 to $200^{\circ} \mathrm{C}$ (Fig. S5, ESI $\dagger$ ), which can be attributed to the mobility of the alkyl chain and corresponds to the thermochromatic transition. ${ }^{27}$ The critical temperature was further verified by the Raman spectra where two main shifts from 1454 to $1513 \mathrm{~cm}^{-1}$ and 2086 to $2117 \mathrm{~cm}^{-1}$ occurred at around $60{ }^{\circ} \mathrm{C}$. In addition, the maximal $\Delta \mathrm{CR}$ also appeared at $60{ }^{\circ} \mathrm{C}$ (inset, Fig. 3a). Furthermore, although the endothermic peak was weaker in the second cycle, it can be completely repeated with a significant chromatic memory (Fig. 6a). To illustrate the rapid colour change, a fast scanning calorimeter (Flash DSC ${ }^{28}$ with a high temperature change rate of $5000 \mathrm{~K} \mathrm{~s}^{-1}$ was employed to further explore the chromatic transition of PA-PDA. Interestingly, the endothermic peak was still present (Fig. 6b), indicating that the reversible thermochromism occurred even at a temperature change rate of $5000 \mathrm{~K} \mathrm{~s}^{-1}$, compared with typically $\sim 1 \mathrm{~K} \mathrm{~s}^{-1}$ in previous reports. ${ }^{21}$

Inspired by the idea that the thermochromism is induced by increased mobility of the alkyl chains, whose transition temperature should be length dependent, we reasoned that the colour transition temperature could be changed by varying the alkyl chain length. To this purpose, a similar PA, $\mathrm{C}_{23}$-GAGAGAGY (Scheme 1b), with two carbon atoms less than $\mathrm{C}_{25}$-GAGAGAGY was synthesized and employed to prepare the corresponding PAPDA. Unsurprisingly, the material displayed similar thermochromatic behavior, but the DSC result (Fig. S6, ESI $\dagger$ ) showed that the transition temperature was about $52{ }^{\circ} \mathrm{C}$, which is $8{ }^{\circ} \mathrm{C}$ lower than that of the $\mathrm{C}_{25}$-GAGAGAGY PA-PDA. Given that the transition temperatures of the strongly bonded peptide chain segments in the structure would be expected to be far higher, we tested the hypothesis that the transition is due to the onset of 

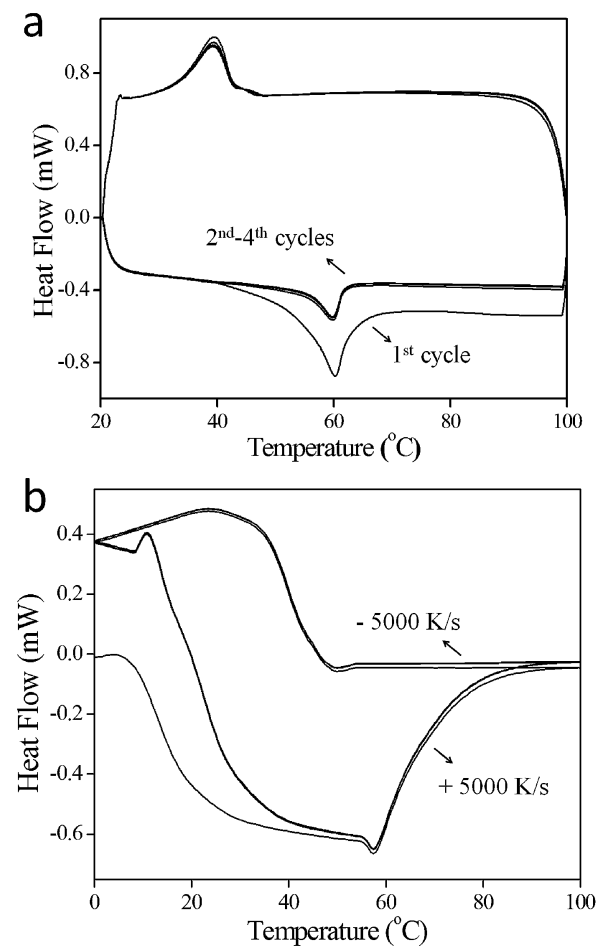

Fig. 6 (a) DSC analysis of PA-PDA. Only one endothermic peak at $60^{\circ} \mathrm{C}$ appeared in the heating process from $20^{\circ} \mathrm{C}$ to $100{ }^{\circ} \mathrm{C}$ and the endothermic peaks completely repeated from the second cycle onwards. (b) Flash-DSC analysis of PA-PDA at a heating and cooling rate of $5000 \mathrm{~K} \mathrm{~s}^{-1}$, with the endothermic peak still appearing.

increased motion in the alkyl segments of the short hydrocarbon chain from a stacked crystal structure to a more disordered rubber-like state above the crystal melting temperature, $T_{\mathrm{m}}$.
To do this, we used the method of Group Interaction Modelling, which is described in detail elsewhere. ${ }^{29}$ The energetic condition for the crystal melt and glass transitions $\left(E_{\mathrm{t}}\right)$ is quantified by the Born elastic instability condition as a defined fraction 0.213 of the cohesive binding energy $\left(E_{\text {coh }}\right)$ of interacting segments of a polymer chain in a Lennard-Jones potential energy well. The energy to attain this condition is provided by the zero point energy $\left(H_{\mathrm{c}}\right)$ and the thermal energy of molecular segment vibrations $\left(H_{\mathrm{T}}\right)$. For the crystal state, $H_{\mathrm{c}}=$ $0.04 E_{\text {coh. }}$. Thermal energy is approximated from the full Debye theory for one dimensional skeletal mode vibrations in terms of the parameters of degrees of freedom per group $(N)$, the molar gas constant $\left(R=8.3 \mathrm{~J} \mathrm{~mol}^{-1} \mathrm{~K}^{-1}\right)$ and the reference temperature $(\theta)$.

$$
\begin{aligned}
E_{\mathrm{t}}= & 0.213 E_{\mathrm{coh}}=H_{\mathrm{c}}+H_{\mathrm{T}}= \\
& 0.04 E_{\mathrm{coh}}+\frac{N^{\prime} R}{3}\left(T_{\mathrm{m}}-\frac{\theta}{6.7} \tan ^{-1}\left[\frac{6.7 T_{\mathrm{m}}}{\theta}\right]\right)
\end{aligned}
$$

Taking a simple characteristic $\mathrm{CH}_{2}$ group as the potentially mobile segment, an infinite chain would have $N=1$ normal modes for tight crystal packing, $E_{\mathrm{coh}}=4500 \mathrm{~J} \mathrm{~mol}^{-1}$ from group additivity tables, and $\theta=550 \mathrm{~K}$. However, the short chains in the model structure need to be adjusted for structural features: the free chain end needs six extra degrees of freedom and the crosslinked end eliminates three degrees of freedom due to restrictions on motion. So for a chain of $n$ atoms, the adjusted degrees of freedom become $N^{\prime}=N(1+3 / n N)$. For $\mathrm{C}_{23}$-GAGAGAGY and $\mathrm{C}_{25}$-GAGAGAGY, $n=10$ and $n=12$, respectively, since that is the number of $\mathrm{CH}_{2}$ groups in the terminal segment beyond the crosslinked sites. Thus, the transition temperature

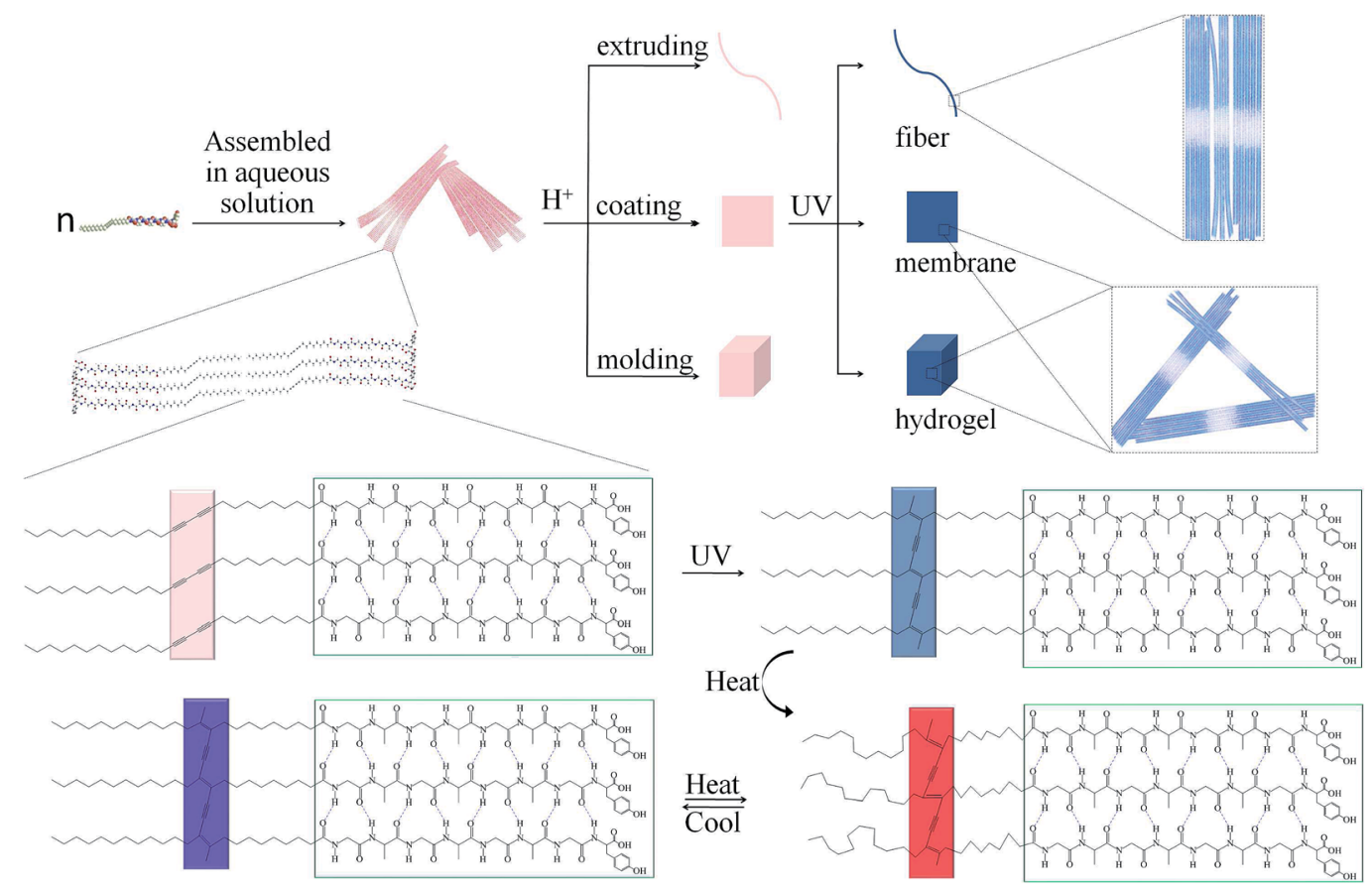

Scheme 2 Self-assembly and subsequent polymerization of PA and thermochromism of PA-PDA. 
can be calculated by solving the simplified energy relation with the specified parameter values:

$$
\frac{281}{1+\frac{3}{n}}=\left(T_{\mathrm{m}}-\frac{\theta}{6.7} \tan ^{-1}\left[\frac{6.7 T_{\mathrm{m}}}{\theta}\right]\right)
$$

We predict that $T_{\mathrm{m}}=52{ }^{\circ} \mathrm{C}$ and $61{ }^{\circ} \mathrm{C}$ for $n=10$ and $n=12$ respectively, which are in good agreement with the observations of the transition temperatures, i.e. $52{ }^{\circ} \mathrm{C}$ and $60{ }^{\circ} \mathrm{C}$ by DSC. The result also verifies the hypothesis that the reversible transition is due to the onset of increased motion in the alkyl segments, with stable peptide segments. Moreover, the modelling equation may be extended to other sensing polymers based on alkyl side chains, which encourages us to investigate further and may shed light on designing a series of fast colorimetric detection and sensing systems.

As a control experiment, the PDA materials obtained from $\mathrm{C}_{25}$ and $\mathrm{C}_{23}$ precursors without GAGAGAGY at the side chain cannot be made into continuous fibres; the PDA films or powders exhibited a thermochromatic transition at a low temperature range of 50 to $80^{\circ} \mathrm{C}$; the colour change from blue to red was slow (typically tens of seconds), and the chromatic transition was not reversible. Therefore, the formation of peptide-based amphiphiles is a key to the extraordinary thermochromatic properties of PA-PDA materials.

\section{Conclusions}

In summary, a continuous PDA fibre has been developed to exhibit ultrafast, reversible thermochromatic transitions at an unusually high temperature of $200{ }^{\circ} \mathrm{C}$ by designing peptidebased amphiphilic precursors (Scheme 2). At least 3 thermochromatic cycles could be completed in 1 second, compared with tens of seconds to minutes for 1 thermochromatic cycle in other polymers, and the reversible thermochromism occurs even at a temperature change rate of $5000 \mathrm{~K} \mathrm{~s}^{-1}$, much higher than the typical $\sim 1 \mathrm{~K} \mathrm{~s}^{-1}$ in other sensing polymers. The formation of a hierarchically assembled structure is responsible for the remarkable chromatism. In addition, a general and effective model is further concluded to quantitatively predict the critical temperature of the chromatic transition and guide the advancement of chromatic materials. Therefore, this work also presents an efficient paradigm in the development of high-performance sensing polymer materials by incorporating peptide-based side chains for hierarchical structures.

\section{Acknowledgements}

This work was supported by the National Natural Science Foundation of China (NSFC 21034003), and the Program of Shanghai Subject Chief Scientist (12XD1401000). The authors thank Prof. Wenbing $\mathrm{Hu}$ and Zhaolei Li (Nanjing University, China) for performing the Flash DSC experiment.

\section{Notes and references}

1 C. Sanchez, H. Arribart and M. M. G. Guille, Nat. Mater., 2005, 4, 277.

2 X. Chen, G. Zhou, X. Peng and J. Yoon, Chem. Soc. Rev., 2012, 41, 4610.

3 X. Sun, T. Chen, S. Huang, L. Li and H. Peng, Chem. Soc. Rev., 2010, 39, 4244.

4 Y. Lu, Y. Yang, A. Sellinger, M. Lu, J. Huang, H. Fan, R. Haddad, G. Lopez, A. R. Burns, D. Y. Sasaki, J. Shelnutt and C. J. Brinker, Nature, 2001, 410, 913.

5 O. Yarimaga, J. Jaworski, B. Yoon and J. Kim, Chem. Commun., 2012, 48, 2469.

6 O. J. Dautel, M. Robitzer, J.-P. Lère-Porte, F. Serein-Spirau and J. J. E. Moreau, J. Am. Chem. Soc., 2006, 128, 16213.

7 B. Yoon, H. Shin, O. Yarimaga, D. Ham, J. Kim, I. S. Park and J. Kim, J. Mater. Chem., 2012, 22, 8680.

8 S. B. Lee, R. R. Koepsel and A. J. Russell, Nano Lett., 2005, 5, 2202.

9 J. Song, J. S. Cisar and C. R. Bertozzi, J. Am. Chem. Soc., 2004, 126, 8459.

10 T. Aida, E. W. Meijer and S. I. Stupp, Science, 2012, 335, 813. 11 S. Zhang, M. A. Greenfield, A. Mata, L. C. Palmer, R. Bitton, J. R. Mantei, C. Aparicio, M. O. de la Cruz and S. I. Stupp, Nat. Mater., 2010, 9, 594.

12 P. Palladino, V. Castelletto, A. Dehsorkhi, D. Stetsenko and I. W. Hamley, Chem. Commun., 2012, 48, 9774.

13 L. Hsu, G. L. Cvetanovich and S. I. Stupp, J. Am. Chem. Soc., 2008, 130, 3892.

14 S. R. Diegelmann and J. D. Tovar, Macromol. Rapid Commun., 2013, 34, 1343.

15 M. van den Heuvel, H. Baptist, P. Venema, E. van der Linden, D. Lowik and J. C. M. van Hest, Soft Matter, 2011, 7, 9737.

16 B. E. I. Ramakers, M. van den Heuvel, N. Tsichlis i Spithas, R. P. Brinkhuis, J. C. M. van Hest and D. W. P. M. Lowik, Langmuir, 2012, 28, 2049.

17 J. Zhang, R. Hao, L. Huang, J. Yao, X. Chen and Z. Shao, Chem. Commun., 2011, 47, 10296.

18 H. Guo, J. Zhang, T. Xu, Z. Zhang, J. Yao and Z. Shao, Biomacromolecules, 2013, 14, 2733.

19 I. W. Gilmour, A. Trainor and R. N. Haward, J. Appl. Polym. Sci., 1979, 23, 3129.

20 A. Reichert, J. O. Nagy, W. Spevak and D. Charych, J. Am. Chem. Soc., 1995, 117, 829.

21 H. Peng, J. Tang, L. Yang, J. Pang, H. S. Ashbaugh, C. J. Brinker, Z. Yang and Y. Lu, J. Am. Chem. Soc., 2006, 128, 5304.

22 Q. Cheng, M. Yamamoto and R. C. Stevens, Langmuir, 2000, 16, 5333.

23 S. Ha, A. E. Tonelli and S. M. Hudson, Biomacromolecules, 2005, 6, 1722.

24 C. W. Bunn and T. C. Alcock, Trans. Faraday Soc., 1945, 41, 317.

25 G. J. Exarhos, W. M. Risen and R. H. Baughman, J. Am. Chem. Soc., 1976, 98, 481. 
26 N. Mino, H. Tamura and K. Ogawa, Langmuir, 1991, 7, 23362341.

27 K. E. Huggins, S. Son and S. I. Stupp, Macromolecules, 1997, 30, 5305 .
28 V. Mathot, M. Pyda, T. Pijpers, G. Vanden Poel, E. van de Kerkhof, S. van Herwaardeng, F. van Herwaardeng and A. Leenaers, Thermochim. Acta, 2011, 522, 36.

29 D. Porter, Group Interaction Modleling of Polymers, Marcel Dekker, New York, 1995. 